International Journal of Advanced Studies in Humanities and Social Science (IJASHSS)

Available online at http://www.ijashss.com

Volume 8, Issue 1 (2019) pp. 1-12

Original Article

\title{
A Comparative Study on Consumer Protection in E- Commerce Law of Iran and European Union
}

\author{
Samaneh Ahmadikhah \\ Graduate student at Farabi Campus of Tehran University, Tehran, Iran \\ *Corresponding Author E-mail: Sam86110@yahoo.com
}

Received: 24 October 2018, Revised: 05 December 2018, Accepted: 20 December 2018

\begin{abstract}
With increasing trend in using the electronic means of communication and trade in the world, the need to enact new laws and regulations with regard to e-commerce law is increasing day by day, where benchmarking of the countries and the leading organizations in this context can be used to provide the measures to encourage the Economic activists and consumers to do their tasks at cyberspace particularly provided with supporting the consumer who are in poor side. In this paper, Comparative Study on Consumer Protection in E-Commerce Law within Iran and European Union has been proposed. The observations, with regard to the studies show that based upon the international character of electronic commerce law and the role of UNCITRAL model law on ecommerce (1996) in Unification of it at international level, this law which includes consumer protection has been also provided with the same basis throughout the world. Nevertheless, the countries and organizations like the European Union with adoption of instructions have made large effort in going through this e-commerce law to get it completed by which developing countries like Iran can get to use such law.
\end{abstract}

Keywords: Consumer Protection, E-Commerce Law, Iran, European Union.

\section{Introduction}

The most important phenomenon ever since the industrial revolution has been mentioned as the rise of ICT and consequently creation of cyberspace. This phenomenon has influenced the prevailing aspects of social life through which its impact on international commerce can be taken; consequently this has led to creation of e-commerce (Hojatzade and Noushadi, 2011). Hence With the increasing development of e-commerce, consumer protection in Cyberspace due to the lack of physical connection between the parties entering to contract should be considered further. This paper aims to take step in this context of discussion. In this regards, firstly Supplier commitments in e-contracts taken in the category of consumer rights have been discussed and later rights and privileges for consumers taken in electronic contract have been defined.

\section{Problem Statement}

Iran in the context of e-commerce is an emerging country, so to achieve the favorable status it is need to extra cost and 
time, however, fundamental measures to expand e-commerce have been made, i.e. one is mentioned enacting e-commerce in 2003; hence, the necessity to expand ecommerce is provided with using other countries' and international organizations' experiences as well as appropriate interaction devices so far as the provision for activities by Private sector, entrepreneurs and consumers would be provided. However, given that the consumer is in a weak contractual relationship, support on behalf of consumer is essential. According to what said earlier, the researcher intended to observe the consumer protection in ecommerce law whereby this topic of discussion was examined in Iran and European Union, a comparison was provided for this. Here, the main problem is asked to what extent Banking Consumer Protection in E-Commerce Law within Iran and European Union is important? While talking about consumer right, it is asked what commitments the supplier undertakes against the consumer? What privileges and rights the consumer has in e-commerce in both Legal Systems. A response to such questions helps to define the common and different points of consumer protection in E-Commerce Law in Iran and European Union.

\section{Research Methodology}

Research methodology aims to help the researcher to adopt a method with the more accurate, easier and faster way to access the response. This research based on the base of the result is categorized in applied research type. The theoretical basis of research was conducted by applying the library sources including books, journals, Persian and English articles and a variety of rules and obligations.

\section{Supplier Commitments in E-Contracts}

\section{Commitment to Give Data}

On the basis of examples of information that must be provided to the consumer, protection law of the consumer rights has defined the cases in this context. The protection law of human rights on the type of information needed to be provided by the supplier regarding paragraph 2 of article 3 has defined that the suppliers are obliged to provide necessary information including type, quality, quantity and information prior to consumption, production date and expiry of consumption for the consumer. The first chapter of e-commerce law on the basis of consumer protection within article 33 has defined that Product vendors and service providers have to provide necessary information in consumers' decision making to purchase or accept the conditions ever since before entering into contract for consumers. These include amongst others, the name, identity, geographical address, and the electronic mail address of the service provider to make it possible to contact him rapidly and communicate with him in a direct and effective manner. These information must also be provided in a form and manner which is easily, directly and permanently accessible. Where a service provider fails to provide this information, he may be liable in damages for breach of statutory duty at the suit of the recipient of a service.

\section{Technical and Functional Characteristics of Goods or Services}

Information are in two categories, the first category includes the information without them entering into contract won't be possible; this is defined clearly in article 342 of civil law. The second category includes the information associated to the 
stage to implement the contract such as the information that unawareness of that can threaten the good for the consumer, mentioning that due to the fact that nothing has brought in civil law along this, and no prediction for none of the contract parties has not taken, so e-commerce and protection law for consumers have not fitted to fill the weaknesses where on Fines have to be paid to provide such information; this won't have any benefit for the consumer so that only the government's benefits would be provided. Such information can be classified into three categories.

\section{Commitment to Providing General and Simple Information}

Based on this commitment, the committed required providing general information about the fundamental properties of matter of commitment and its implementation conditions. The most conventional and the simplest method to provide such a commitment has been mentioned as informing the consumer through attaching a label with required information on the packages containing products manufacturer(Ghasemi, 1996).

\section{The Obligation to Provide Information about the Potential Risks}

Proposing such a commitment attains its importance from the diversity of services and goods particularly the chemical products with complicated formulas throughout the society and needing to observe the necessary prediction in using them and needing to being provided with information required. Because lack of enough familiarity with the dangers likely stemmed from incorrect applying modern products in most of the cases would be found with irreparable losses.

\section{The Obligation to Provide Information Consulting}

In this type of commitment, the expert is required to provide detailed information on the goods under the contract and applicable information regarding the likelihood of project success and its highefficacy performance to the non-specialist in the technical and financial contexts so that the non-specialist can adopt the necessary information to purchase goods.

For instance, the seller and expert in the field of computer has to give information to their consumers on the specific potentials of computer proposing to their consumers, providing the capability and return percentage with regard to the project for the purchaser who is not enough specialized in this field. Negation of such commitment would be followed by prosecution for the one who avoided doing his/her tasks (Salehi, Ibrahimi, and Salari rad, 2012).

\section{Information Regarding the Identity of the Seller}

Given that the buyer does not see his/her favorite e-commerce for product, so the supplier provides is committed to provide the necessary information to the buyer. The information with regard to the article 33 of e-commerce law which has to be provided for the consumer includes the information associated to the identity of the seller mentioned in paragraphs B and $\mathrm{C}$ this article.

\section{Prices}

In electronic commerce, the price must be stated in a clear and conspicuous way, mentioning that even if the proposal of the contract was not taken, the price announced has to consist of:

Does the price include taxes and shipping costs? 
Method of payment of goods or services

Actual costs of sales using the remote sale

\section{Period When the Offer is Valid}

Consumer has to be provided with the conditions of contract including the period when the offer by the suppliers is authentic or not.

\section{Right of Withdrawal}

In the light of Right to withdrawal for the consumer, the seller is obliged to inform the purchaser of the right to withdraw whereby it has to be stated that this is not true about the sellers of European Union and the sellers throughout the world.

This means the instructions proclaimed in Europe on consumer rights impose the obligations on the sellers across the countries who are the membership at European Union against consumers whereby this won't be true in Rest of the World (Dablephon and Zarkalam, 2012). Yet, as would be discussed later, article 37 of Iran's e-commerce has defined the consumer's right to withdraw with benchmarking of the instructions in European Union.

\section{Deadline}

The consumer has to be informed of the time needed to send goods ordered, where by the approximate deadline failed to be predicted, the maximum time to carry the goods has to be specified rather than the Contractual equilibrium would be influenced.

\section{Guarantees}

Client in cyberspace like any other buyer is provided with Warranty against hidden defects and Warranty understanding, where this, in Iran law, is defined in the implied terms. Such guarantees are relatively associated to being committed to provide information, because if the seller does not be the owner of a property intending to sell it, so the seller is committed to the truth to the purchaser; otherwise, warranty of understanding as mentioned in article 391 of civil law has to pay fined for the damaged received by consumer. The conditions for acting Warranty against hidden defects in online sale with the conditions extracted by traditional legal procedures to sell that good in a real environment would not be different (Dablephon and Zarkalam, 2012). One of the types of defects is the defect caused by failure to disclose information. Goods, due to a failure to provide necessary and appropriate information about the risks and potential losses and how to exploit it may be considered defective. Thus violating the obligation to provide information not only creates liability for the supplier, but also causes goods sold to be considered defective. Non-disclosure of information in cases mentioned above reduces abuse and exploitation of it- and this leads to a deterioration of the sales (Salehi, Ibrahimi, and Salari Rad, 2012). Mazo believes that the seller has to provide the good for the purchaser to use it, and then he has to provide the purchaser with the necessary information to use the object sold (Joneidi, 2002).

\section{Commitment to Give the Data in European Union}

E-commerce suppliers rather than traditional ones are obliged to provide more information for the purchaser before entering into the contract; this turns back to lack of consumer's knowledge on the face to face exchanges.

Distance contracts are any contract concerning goods or services concluded between a supplier and a consumer under an organized distance sales or service- 
provision scheme run by the supplier, who, for the purpose of the contract, makes exclusive use of one or more means of distance communication up to and including the moment at which the contract is concluded. According to the distance contracts, the supplier has to provide the purchaser with the information as follows:

Identity of seller

The goods and services proposed

\section{Contract and commitments}

Distance guideline requires to supplier informs the consumer with his name in a proper occasion before signing the contract. In such contracts, it is required to pay in advance and likewise the seller's address has to be proposed.

The information associated to goods and a service proposed has to be consisted of:

The main features of goods and services

Price including all taxes...

All the prices related to delivery

Additional costs of communicative devices

A period when the proposal and price sustain valid

The least duration of each contract implemented constantly

Finally, the EU requires that the consumer be supplied with a substantial amount of information concerning contract and obligations that arise under it before conclusion. For example, the Distance Directive specifies that the consumer must have a complete understanding of means of payment, delivery or performance of the contract and the "existence of a right of withdrawal." In addition, "the consumer must receive written confirmation ... [of the information provided] in good time during the performance of the contract, and at the latest at the time of delivery." The consumer must also be provided with written information regarding the geographical address where he may send complaints, the existence of after-sales service and guarantees and the conditions for cancellation of long term or indefinite contracts (Cordera, 2001).

According to the fact that United Nations Commission on trade law issued the UNCITRAL Model Law in 1996 and provided it for the states as a sample, many countries applied this model whereby the same law can be seen grounded on this point in international level.

\section{Obligation to Supply Goods and Services in Contract}

In addition to the obligation to provide information that was dealt, another commitment that has been undertaken by a supplier of electronic contracts for goods and services is the very commitment to providing these contracts. In civil law, principle is that if a certain property is sold to another one, so, the same property must be submitted where only in The overall sales or sales to the sample, the possibility to submit one of the samples of sale by the way the seller determines exists. Indeed, submitting the same good in domestic legal system except for the properties sold in wholesale does not exist. On the basis of article 40e-commerce law, the supplier can deliver the similar good or services promised to provide for the consumer provided that acclaiming that before entering into contract or during it.

The important point lied in the fact that the fundamental of this rule the first has been accepted in domestic law system; meanwhile, it was not limited to the sale of the entire good where the rule of submitting the same good has been 
accepted so that as acclaimed in the presupposition by seller, if acclimated before the contract signed resulting in parties' agree on signing contract, this would be accepted. Yet, agree on submitting after contract to indicate whether not being accepted by parties, would be followed by doubt (Pourseyed, 2007). provisions of article 40e-commerce law can be found different from the general regulations of contract in two sides: the first is that the contract has to be certain where the jurists believe that if ambiguity seen in the contract, so it would be negated; second is that by an assumption that the similar good or service be original, then it has to be accounted as a conversion of commitment against the contract. As a result, two contracts are signed in fake and/or two issues enter into contract in a fake (Alsan, 2011). It seems that the phrase of legislator (during signing the contract), has not to have conflict of interest with the regulations of contract law because article 40 knows delivery or submitting similar goods or services by the supplier grounded on that the point that the contract before getting signed or during it has to be submitted not referring to the time after the contract. However, if accepting submitting the same good by seller after signing contract as brought in article 40 , so no conflict of interest is seen regarding the regulations of contract law because this can lead to a new offer whereby it can be accepted or rejected by the purchaser. Nonetheless, as said, the article 40 exclusively includes the subjects at which the supplier before or during signing the contract, submits the similar goods or services to the consumer promised him to send the items on time.

Further, on the basis of accepting the idea by submitting the items before signing the contract as assumed the conflicts and agreements by the parties, so it seems due to one of the items of void conditions as believed against the imperative rules.

Article 342, the seller has to refer to a certain contract not believed its capability sufficient, this is totally in accordance with conflict of interests among parties. It seems article 40 of e-commerce law is analyzed in this way; as brought in article 40 , the same goods or services are those goods and services known similar the goods entered into contract previously where in viewpoints of the contractors, are those goods and services with the same value and characteristics whereby purchase would be true, thus, the buyer refers to a specific contract and the seller has the right to choose the purchaser (Katoozian, 2005). Give what said above, it seems that there is no conflict of interest in article 40 with the general regulations of contract. Indeed, the same goods or services mean using the same contract for them in order sign a contract for the services.

\section{Exceptions in Consumer Protection in Iran}

These exceptions have been provided in articles 42 and 47 of e-commerce law adopted a law passed by the Council of Ministers in a meeting dated 2004.

\section{Consumer Rights and Privileges at Electronic Contracts}

\section{The Right of Withdrawal Electronic Contracts}

The Regulations set out how the cancellation notice must be set out. The cancellation notice requires the identity of the trader to be shown i.e. the legal identity, not just your trading name. In practical terms the cancellation notice and the written agreement to start work in the 
contract with the consumer has to be included. In either case the cancellation notice must be given at the time agreed to do the work and before any work is started. The consumer has to act at least seven days for Right to cancel the contact without going under paying fines and/or submitting a reason. The only fine on the shoulder of consumer is paying back the good. Starting by exercising the right of withdrawal in case of sale of goods, from the submission date of the sale to the consumer and in the case of sale of services, would be started from the time contract signed (Section "A" of Article 38). However, starting with exercising the right to cancel the transaction undertaken by the supplier obliged to provide after giving the thorough information on the contract, (paragraph "b" of Article 38). By using the right to cancel the contract, the supplier is obliged to pay back the amount received without hesitation where no fine has to be taken (paragraph c of Article 38). Anyhow, not to let the consumer use the right to cancel, it is necessary for the specialists to provide necessary information on the contract at any time about the procedure for the formation of contract to the consumer. One of the conditions to exercise the right to cancel is that the possibility to face to face encounter does not exist for the supplier and consumer. Hence, if negotiation between supplier and consumer exists previously and then the contract gets signed, then it cannot be mentioned the distance contract at which there would not exist the right to cancel. Further, if the notification of accepting the contract acclaims by distance communication and willing to accept the contract be in face to face status so the distance contract would not come to realize.

\section{Exceptions in the Right of Withdrawal Electronic Contracts in Iran}

Exceptions in The right to cancel electronic contracts in accordance with paragraph (d) of article 38 of Iran's e-commerce law with recourse to paragraph (a) of article 79 of e-commerce law issued in 2003 was issued as follows: consumer in the light of following factors by specific conditions at goods and services would be delinked of the right to cancel electronic contracts, as this is mentioned in paragraph $\mathrm{d}$ of article 38 of ecommerce law unless the parties agree followed by a way to go through it.

On the services, if the consumer agreed in a case of submitted services before end of seven days of working.

Providing service to deliver food or other goods that are used daily.

Goods or services with a price determined by fluctuations in the financial markets, which cannot be undertaken by the supplier.

Goods made with individual characteristics of consumer that are clearly personal or because in nature they cannot be withdrawn, or having the ability to be quickly spoiled.

Audio and video tapes and computer software packages that have been opened by the consumer.

Newspapers, periodicals and magazines according to the press law definition.

\section{The Right of Withdrawal the European Union}

Consumers in Europe have the right to terminate the contract within 7 working days. The first moment is the date at which the good received where on it is no need to acclaim cancellation of contract whether necessary details of goods and services not provided by suppliers to the consumer, this duration would be lasted to three months so that the right to cancel contract 
even after the good received would be remained. It is stated in the light of cancellation of contract by consumer, the amount necessary to pay back would be estimated within 30 days (Nouri and Nakhjavani, 2011). As stated based upon Iran's e-commerce law, the supplier is obliged to pay back the amount received as soon as possible. At the European guidelines at which the right to cancel the contract has been forecasted, the supplier committed to inform the customer from the right to cancel the contract whereby it is unlikely acting this right never get started followed by it would not ever terminated. For this, according to European distance sale guideline, to prevent misuse of consumer, the deadline to cancel would be limited to three months.

These three months start from the early time the good received by consumer and the services entered to contract signed. When the supplier acts to provide necessary information, the deadline to cancel contract would be from the time the information provided within the seven working days (The end part of 1 article 6 distance sale guideline). While article 38 ecommerce law of Iran does not determine such limitations cancel the right contract for consumer (Alsan, 2012). It seems forecasting this limitation, however, avoids misuse by consumer, in cases the profit gained by signing the contract for the suppliers rather than the punishments taken in acting violation against providing information, it is likely the supplier goes through to the side not to inform the consumer from the cancellation right whereby this would in the end lead to misuse by supplier. Instead of deadline limited on the right to cancel the contract by consumer, the rule against loss can be acted in the cases while the supplier can approve the consumer is informed of the right to cancel the contract whereby misusing the consumer can be avoided.

It has to state that in Iran the commitment undertaken by the supplier regarding part $\mathrm{C}$ of article 34 on submitting information to the terms and conditions associated to cancellation of contract, indicates commitment to inform the customer from the right to cancel the contract has been accepted in e-commerce law. According to part B of article 38, starting to act the right to cancel the contract after the information provided would come to realize where on the supplier is obliged to submit those information.

\section{Exceptions of Right to Withdrawal in European Union}

On the basis of the right to withdrawal the contract within European Union, there are exceptions as follows using them together in Iran's law would make clear the differences and similarities in 2 system laws:

The services carried out as agreed to be provided for the consumer

The good or service which its cost depends on the financial fluctuations at market mentioned beyond from the supplier's authorities

The good defined in partial

Perishable goods which lose their value, such as electricity, flowers and newspapers

Strips sealed, audio- video or opened software

Gambling and lottery contracts

\section{The Possibility of Complaints to Legal and Civil Organizations}

According to the first part of article 48, legal and civil Organizations protecting the 
rights of consumers can appealed to as the plaintiff. Since the consumers roughly do not involve the individuals in the society who have not sufficient condition or opportunity to complain about products and service found with deficiencies, so the existence of organizations acting to receive the complaints and submitting them to regulatory authorities is a part of in-depth approach provided to supply the general benefits. In Iran, in addition to the ecommerce law, provided for consumers, the law dedicated to consumers addressed predicting the committees supporting the law of consumers and the jurisdiction of these agencies (Alesan, 2012). European consumer organization, a coalition of independent national consumer organizations from all EU member states and European countries is Europe, continues its activities.

\section{Consumer Protection against Unfair Contractual Terms in Iran}

After defining right of withdrawal and possibility of complaints by legal and civil organizations as the rights and privileges of the consumer, it is addressed the consumer's third right to protect against unfair contractual terms. Unfair contractual terms in Iran from the scratch in literature did not find, but, support from the one where the balance disturbed harming him has assumed many times a go in Islamic law (Sardoei Nasab and Kazempoor, 2011). Iran's e-commerce law addresses unfair contractual terms not in complete just provided in an in-depth article:

Using unfair contractual terms as well as exercising unfair contractual terms harming the consumer would not come effective (article 46). According to the fact that the unfair contractual terms have been used in complete in this article, determining the instances of unfair contractual terms have been provided for the judge in complete whereby due to the conflict of interests among the judges in determining the instances, the discrimination has been appeared in different cases. In addition to this law, there exist three other laws involving influence of unfairness theory mentioned as follows:

Article 179 of Iran's Maritime Law Act 1964, any article by rescue and help in the light of danger signed, found by court unfair, might be cancelled or changed by every of parties. Law on General Policies within Article 44 of the constitution of the Islamic Republic of Iran in article 45 of this law, have assigned with six instances to misuse the superior position where one of those mentioned as imposing the unfair contractual terms. The law of consumer protection issued in 2009 in article 1-5, has acclaimed one of the components of unfair contractual terms as imposing the unfair contractual terms. Unfairness has not defined in above where no instance has been proposed.

\section{The Approach by European Union on the Basis of Unfair Contractual Terms}

In spite of Iran's law, unfair terms within article three by Council European Union guideline has been defined as, unfair term conveys to a term not mentioned in negotiation by parties provided that being against the wisdom resulting in inequality in rights and commitments of parties called upon as loss for consumer. According to second paragraph of article three, this guideline at the entire contracts and terms provided as draft not make the consumer to affect its content, called as such contracts not entered to the negotiation. The authors who write this guideline knew that two criteria as disagree on goodwill and inequality in sale cannot meet all the likely mistakes in 
applying this rule. For this, a list of terms forecasted where they mainly symbolized and did not mention its generality so that the judges can call upon other terms including article three and finally cancel it (Sardoei nasab and Kazempoor, 2012).

Unfair terms in European contracts' law principle are as follows: according to this principle to call the unfair terms, three types of terms have to be called upon: 1the terms associated to poor party, 2- the terms associated to strong party, 3- the term not mentioned in negotiation.

The criterion taken for poor party include poor party's trust to opposite party, economic pressures or essential needs by poor party, unawareness, lack of skill to enter into transaction and bargaining. The criterion associated to strong party includes the strong party's awareness on the poor party's situation that might lead to misuse by the strong party having the excessive profit. The third criterion grounded on terms out of negotiation where these terms assigned to unfair terms not entered into negotiation in dependence while mentioned against goodwill and fair behavior; further, this might lead to lack of balance between rights and obligations stemmed from contract to against terms. Hence, unfair terms defined in European Union so that a variety of criteria has been determined for unfair terms, while this is used as a term on the whole in Iran.

\section{Conclusion}

Comparative Study on Consumer Protection in E-Commerce Law within Iran and European Union defined the similarities and differences existing in both systems help us to use the useful experience of other companies, detecting Strengths and Weaknesses of the legal system of country in order to take step to resolve the deficiencies and weaknesses existing in the country. The results of this research show that the e-commerce law inherently in nature found in international level not relied on a specific legal system where also United Nations Commission on Trade Law issued the UNCITRAL model law on e-commerce in 1996 in unification of this law has played a leading role. This has caused the approach issued by the countries grounded on the issues associated to the e-commerce law such as consumer protection law have been provided with the same legal bases, whereby a variety of organizations like the Europe Union have taken step to issue the instructions provided in this relation. ECommerce Law of Iran, however, found as a big provision along with the phenomenon of globalization, so deficiencies exist whereby amendment of law and/or issuance of the legislations to interpret them have been found resolving those deficiencies; hence, it is recommended to get informed the consumer with the information where unawareness of them makes the good threaten for the consumer by which the losses enter to the consumer. Further, on the basis of limiting the right to withdrawal the three-month deadline for the instruction of sale by distance contract in Europe, it is recommended in the cases the supplier manage to approve informing the consumer of the right to withdrawal the contract, exercising the regulation found with any harm whereby it can prevent from the consumer to be misused. Another recommendation is that, in the regulations by Iran, a definition of the unfair contractual terms have to be defined, proposed clearly where on other cases are needed to be declared in the law mentioned essential for the research importance and further studies. 


\section{References}

Alesan, M. (2012). Electronic Commerce Law, Samt, 154171-172195.

Alva, J.K. (1998). Definition by consumer, translated by A. Qadak, Shahid Beheshti University, School of Law Legal Research Quarterly, No. 30 -29.

Bagheri, P. and Halili H.K. (2011). Electronic Commerce, Law and Consumer Protection: Reference to Iranian Law Ilam Azad University, Iran \& Phd Candidate, Universiti Kebangsaan Malaysia Faculty of Law, University Kebangsaan Malaysia.

Consumer Rights Protection Act, adopted on 2009, Official newspaper, No. 36965/13 dated 2009.

Cordera, M. (2001). E-Consumer Protection: A Comparative Analysis of EU and US Consumer Protection on the Internet, Academic journal article from Rutgers Computer \& Technology Law Journal.

Dabelphon, Z.L. and Zarkalam, S. (2011). Electronic Commerce Law, publication of Shahr Danesh, pp. 91.

Distance Selling Directive, i.e. Directive 97/7/EC of the European Parliament and of the Council of 20 MAY 1997 on the Protection of Consumers in Respect of Distance contracts.

Ghasemi, H.A. (1996). A brief review of theoretical perspectives obligation to give information of contract in perspective of French Law, Journal of the Bar Association, No. 164, pp. 95-99.

Hojat Zadeh, A. and Noshadi, E. (2012). International law governing electronic contracts (comparative study), Journal of International Law, No. 44, pp. 264.
Huffmann, H. (2004). Consumer Protection in E-Commerce, UNIVERSITY OF CAPE TOWN. Faculty of Law - School for Advanced Legal Studies.

Iran maritime law, issued in 1987.

Izadiphard, A.A. and Kavyar, H. (2009). consumer protection in e-commerce contracts, comparison between European union and the Islamic Law, Notary Association and the Fellowship Office, Association Journal, No. 100, January, p 5.

Joneidi, Laya (2002). Comparative Study of the obligation to give information with an emphasis on common law systems, Journal of Law and Political Sciences, Tehran University, No. 56. Pp. 1.

Katoozian, N. (2005). Civil Rights Foundation (Lessons from certain contracts), Volume 1, Treasure of Knowledge, p. 46.

Langroodi Jafa'ri, M.J. (2002). Terminology of law, Ganj danesh publication, p. 615614.

Law on Amendment of the Law on Direct Taxation adopted on 2002.

Law on Electronic Commerce, adopted on 2003.

Nouri, M.A. and Nakhjavani, R. (2011). Electronic Commerce Law, Ganj Danesh publication, p.151.

Pourseyed, B. (2007). The Law of Electronic Commerce and its innovations, legal Journal, No. 59, p. 59.

Regulations implementing Article 48 of the Law of Electronic Commerce, adopted on 2005.

Salehi, J., Abraham, J., and Salari Rad, M. (2013). Principles and scope of the 
obligation to provide information to consumer goods, Journal of Civil Rights, Volume 1, Issue 1, p. 74-61.

Sardoei Nasab, M. and Kazem Poor, S.J. (2012). Components of unfairness of contract, the law of Justice, No. 75, p. 3773.

The implementation of the general policies of Article 44 of the Iranian constitution, adopted on 2007.

How to cite this article: Samaneh Ahmadikhah, A Comparative Study on Consumer Protection in E-Commerce Law of Iran and European Union. International Journal of Advanced Studies in Humanities and Social Science, 2019, 8(1), 1-12.

http://www.ijashssjournal.com/article 84105.html 